Gut, 1973, 14, 502-505

\title{
The significance of enzyme histochemical patterns in carcinomas of the large intestine in man
}

\author{
F. McGINTY, G. DELIDES, AND D. HARRISON \\ From the Department of Pathology, the University of Sheffield
}

SUMMARY The activities of 13 enzymes in $\mathbf{4 0}$ carcinomas of the large bowel have been studied using histochemical techniques. Five enzymes-non-specific esterase, monoamine oxidase, succinate dehydrogenase, cytochrome oxidase, and acid phosphatase-commonly show much less activity in the tumours than in adjacent normal colon. The tumours have been classified based upon the number of enzymes which show marked reduction in activity in each tumour (types 1-5). The enzyme histochemical type and the size of the tumours have been jointly correlated with the presence of lymph node metastasis. Small type 1 or 2 tumours do not appear to be associated with metastatic disease. Small type 5 tumours were commonly associated with secondary carcinoma in the lymph nodes. Large tumours (greater than $25 \mathrm{sq} \mathrm{cm}$ surface area) of any histochemical type were frequently associated with lymph node metastasis. Discussion of the possible reasons for these findings and their clinical significance is presented.

Previous histochemical studies of the enzymes in proliferative conditions of the large intestine have been primarily concerned with detecting possible differences between benign and malignant neoplasms (Wattenberg, 1959a and b; Nachlas and Hannibal, 1961; Czernobilsky and Tsou, 1968). Although information on the enzyme histochemistry of rectal and colonic carcinomas is available from such studies, the extent to which the enzyme histochemical patterns vary between tumours and the clinical significance of such variability has not been studied.

The purpose of the present work was to examine in detail the frequency and possible clinical significance of the enzyme histochemical differences between individual carcinomas of the large bowel.

\section{Materials and Methods}

Tissue from 40 patients with carcinoma of the large intestine was studied.Within 10 minutes of resection, the intestine was opened and irrigated with saline and pinned out. A perspex viewer was placed over the tumour and adjusted so that the undersurface of the viewer touched the tumour surface without compressing it. The outline of the tumour was drawn on the perspex. This outline was transferred to tracing paper and subsequently to 1 millimetre

Received for publication 14 March 1973. squared graph paper. The areas within the outline were measured by planimetry. Small tumour areas were checked by counting squares on the graph paper within the outline. Blocks of tumour and adjacent mucosa were snap frozen in liquid hexane at $-70^{\circ} \mathrm{C}$ using solid $\mathrm{CO}_{2}$ and absolute alcohol mixture as coolant. Serial frozen sections were cut at $10 \mathrm{~m} \mu$. Two sections, one test and one control, were mounted directly onto each slide. The sections to be used for the study of the hydrolytic enzymes were postfixed in acetone at $4^{\circ} \mathrm{C}$ for one hour. The remainder were allowed to dry at room temperature for five minutes. Thirteen enzymes were studied in each of the $\mathbf{4 0}$ tumours. The sections were incubated in the appropriate media using the open perspex ring technique (Chayen, Bitensky, Butcher, and Poulter, 1969).

The histochemical methods used, the incubation periods, the temperature of incubation, and the nature of the controls are given in table $\mathbf{I}$.

Several other sections from each block were fixed in Wolman's acetic alcohol fixative (Drury and Wallington, 1967) for 10 minutes and stained with haematoxylin and eosin. The remainder of the specimen was fixed in formol saline for routine histological study. All identifiable lymph nodes were taken from each specimen to assess the lymphatic spread of the tumour.

The grading of enzyme activity was done sub- 


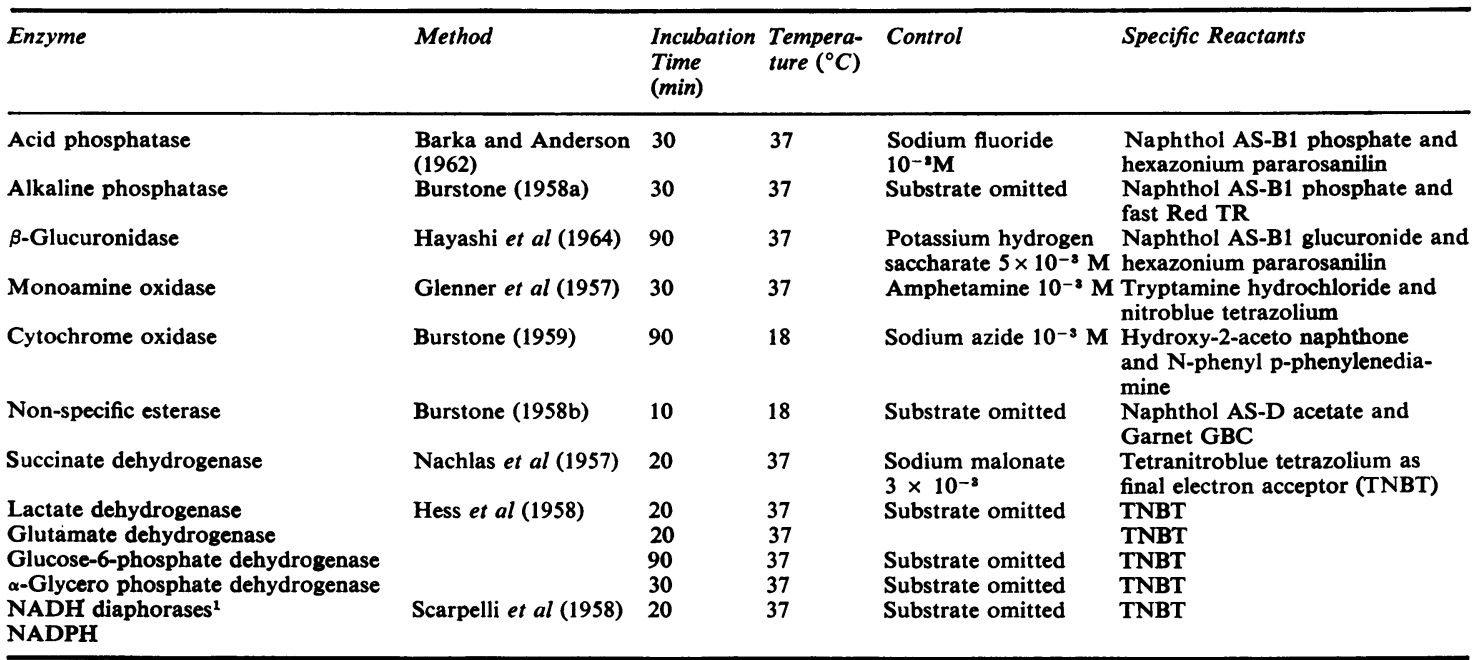

Table I A summary of the histochemical methods

${ }^{3} \mathrm{NADH}$-dihydronicotinamide adenine dinucleotide, NADPH-dihydronicotinamide adenine dinucleotide phosphate.

jectively by viewing with a low-power objective at $\times 10$ magnification. The following scheme was adopted: -2 indicates a marked reduction in an enzyme's activity in the tumour compared to its activity in adjacent histologically normal bowel; -1 means the activity in the tumour is less than that of the normal bowel; 0 indicates that the enzyme activity in the tumour and the normal bowel are the same; +1 means a relative increase in the enzyme activity in the tumour; and +2 indicates a marked increase of enzyme activity in the tumour compared with that in the normal bowel.

\section{Results}

The variation in activity of each of the 13 enzymes in the $\mathbf{4 0}$ tumours studied is given in table II.
Five enzymes commonly show marked relative reduction in activity $(-2)$. These are non-specific esterase, monoamine oxidase, acid phosphatase, succinate dehydrogenase, and cytochrome oxidase. Each tumour has been classified type 1 to type 5 based on the number of enzymes within it which show markedly reduced activity (table III). The enzyme or enzymes involved in each group do not vary.

A relationship exists between the enzyme histochemical type and the degree of differentiation of the tumour (table IV). Poorly differentiated tumours do not show type 1 or 2 histochemical patterns and well differentiated tumours do not show the type 5 pattern.

An intense lymphoreticular infiltrate within the tumour is seen only where the pattern is type 1 or 2 .

\begin{tabular}{|c|c|c|c|c|c|c|}
\hline \multirow[t]{2}{*}{ Enzyme } & \multirow[t]{2}{*}{ Normal Staining } & \multicolumn{5}{|c|}{ Grade of Activity } \\
\hline & & +2 & +1 & 0 & -1 & -2 \\
\hline Glucose-6-phosphate dehydrogenase & Strong & 5 & 16 & 18 & 1 & $\mathbf{0}$ \\
\hline Succinate dehydrogenase & Strong & $\mathbf{0}$ & 1 & 15 & 5 & 18 \\
\hline NADH diaphorase & Strong & 4 & 13 & 21 & 2 & $\mathbf{0}$ \\
\hline NADPH diaphorase & Moderate & 3 & 12 & 24 & 1 & 0 \\
\hline$\beta$-Glucuronidase & Moderate & $\mathbf{0}$ & $\mathbf{0}$ & 8 & 22 & 10 \\
\hline Cytochrome oxidase & Strong & $\mathbf{0}$ & 2 & 13 & 6 & 19 \\
\hline$\beta$-Glycerophosphate dehydrogenase (NAD-linked) & Strong & $\mathbf{0}$ & 1 & 16 & 7 & 4 \\
\hline Non-specific esterase & Strong & $\mathbf{0}$ & $\mathbf{0}$ & $\mathbf{0}$ & $\mathbf{0}$ & 0 \\
\hline Monoamine oxidase & Strong & $\mathbf{0}$ & $\mathbf{0}$ & 7 & 4 & 9 \\
\hline Glutamate dehydrogenase & Strong & 1 & 6 & 22 & 11 & $\mathbf{0}$ \\
\hline Alkaline phosphatase & Negative & 0 & $\mathbf{0}$ & 40 & $\mathbf{0}$ & 0 \\
\hline
\end{tabular}

Table II Variation in enzyme activities of carcinomas of large intestine 


\begin{tabular}{|c|c|c|}
\hline $\begin{array}{l}\text { Number of Enzymes with Markedly } \\
\text { Reduced Activity }\end{array}$ & $\begin{array}{l}\text { No. of } \\
\text { Cases }\end{array}$ & Enzymes Involved \\
\hline $\begin{array}{l}1 \text { (type 1) } \\
2 \text { (type 2) }\end{array}$ & $\begin{array}{l}5 \\
9\end{array}$ & $\begin{array}{l}\text { Non-specific esterase } \\
\text { Non-specific esterase and monoamine oxidase } \\
\text { Non-specific esterase and acid phosphatase }\end{array}$ \\
\hline $\begin{array}{l}3 \text { (type 3) } \\
4 \text { (type 4) }\end{array}$ & $\begin{array}{l}6 \\
3\end{array}$ & $\begin{array}{l}\text { Non-specific esterase and acid phosphatase and monoamine oxidase } \\
\text { Non-specific esterase, monoamine oxidase acid phosphatase, and cytochrome oxidase } \\
\text { Non-specific esterase, acid phosphatase, monoamine oxidase, and succinate } \\
\text { dehydrogenase }\end{array}$ \\
\hline 5 (type 5) & 17 & $\begin{array}{l}\text { Non-specific esterase, acid phosphatase, monoamine oxidase, cytochromic oxidase, and } \\
\text { succinate dehydrogenase }\end{array}$ \\
\hline
\end{tabular}

Table III The number of enzymes showing marked reduction in activity in large bowel carcinomas

\begin{tabular}{lll}
\hline Degree of Differentiation & Types 1+2 & Type 5 \\
\hline Well differentiated & 8 & 0 \\
Intermediate differentiation & 6 & 8 \\
Poorly differentiated & 0 & 9 \\
\hline
\end{tabular}

Table IV Enzyme histochemical types and the degree of differentiation of large bowel tumour

There is no direct association between lymph node metastasis and the enzyme histochemical type. However, when the area of tumour and the enzyme histochemical type are considered together then differences in the frequency of lymph node metastases are found (table V). None of the small tumours (less than $25 \mathrm{sq} \mathrm{cm}$ area) with type 1 or 2 histochemical patterns have lymph nodemetastases even though the tumour had penetrated the full thickness of the bowel wall in five of the eight cases. Metastatic tumour is frequently found in the regional lymph nodes in small type 5 tumours even in the absence of penetration of the bowel wall. In this group blood vessel invasion is commonly seen. Large tumours of any histochemical type frequently have lymph node metastases.

There is no apparent relationship between the enzyme histochemical type of tumour and the age or sex of the patient or the site of the carcinoma within the large intestine.

The enzymes which most commonly have increased activity in the tumours are lactate dehydrogenase, glucose-6-phosphate dehydrogenases, and the two diaphorases (table I). Lactate dehydrogenase and glucose-6-phosphate dehydrogenase activities are often raised together and this pattern predominates in well differentiated tumours. Increased lactate dehydrogenase activity alone is most frequently associated with poorly differentiated lesions.

The two diaphorases are often increased in activity in the tumours and this is seen in both well differentiated and poorly differentiated lesions.

\section{Discussion}

It is possible to classify large bowel tumours according to their histochemical pattern and size. To determine whether this classification has either biological or clinical significance it is necessary to discover which parameter of tumour metabolism the enzyme histochemical pattern represents.

The reduced activities of certain enzymes in proliferative disorders of the large intestine may reflect the rate of growth of the lesions. Decreased activities of acid phosphatase, aminopeptidase, non-specific esterase, cytochrome oxidase, succinate dehydrogenase, and monoamine oxidase are often found in both benign and malignant neoplasms and also in hyperplastic lesions (Wattenberg, 1959a and b; Nachlas and Hannibal, 1961; Czernobilsky and Tsou, 1968). The common feature in all of these conditions is the accelerated rate of growth. The enzymes with reduced activity are those which are

\begin{tabular}{llll}
\hline Histochemical Type & Area Covered by Tumour & Lymph Node Metastases Present & Lymph Node Metastases Absent \\
\hline \multirow{2}{*}{1 and 2} & Less than $25 \mathrm{sq} \mathrm{cm}$ (small) & 0 & 7 \\
& Greater than $25 \mathrm{sq} \mathrm{cm}$ (large) & 6 & 1 \\
3 and 4 & Less than $25 \mathrm{sq} \mathrm{cm}$ (small) & 2 & 4 \\
& Greater than $25 \mathrm{sq} \mathrm{cm}$ (large) & 3 & 0 \\
5 & Less than $25 \mathrm{sq} \mathrm{cm} \mathrm{(small)}$ & 8 & 6 \\
\hline
\end{tabular}

Table V Enzyme histochemical type, the area covered by the tumour, and the presence of lymph node metastases 
not essential for the process of rapid growth of the tissue, being neither concerned with the provision of energy under conditions of relative oxygen lack nor the production of cofactors necessary for nucleic and protein production.

We suggest that the number of these enzymes which show marked reduction in activity in large bowel carcinomas may be proportional to the rate of tumour growth. If this theory is valid, there should be a corresponding increase in activity for those enzymes responsible for anaerobic energy production and the production of cofactors for nucleic acid synthesis. The observed increases in the activity of lactate dehydrogenase and the diaphorases indicates the increased activity of the glycolytic pathway which linked via the diaphorases results in anaerobic energy production.

Increased activity of the pentose phosphate shunt enzyme glucose-6-phosphate dehydrogenase was frequently observed in the tumours studied. Production of NADPH by this pathway is raised, an important cofactor for nucleic acid biosynthesis.

This interpretation of the enzyme histochemical data would explain the relationship to the degree of differentiation of the tumour, the consistency of the enzymes involved, and the lack of direct correlation with lymphatic metastasis.

The area of the tumour is important to this classification. If the enzyme histochemical pattern represents the rate of growth of the lesion then the size will reflect its duration. The length of time that the carcinoma has been present will be important in determining the possibility of lymphatic metastasis.

The clinical significance of this enzyme histochemical classification will not be clear until the long-term survival study in progress has been completed. However, two points are worth noting at this stage. In certain groups (eg, small type 1 tumours) it appears possible to predict the presence or absence of lymphatic spread. The importance of the extent of spread of the carcinoma at the time of operation in determining the ultimate prognosis is well established (Dukes, 1960). The difficulty lies in detecting the presence of such spread with certainty. Secondly, it has been found in this study that both large type 1 tumours and small type 5 tumours may have lymph node metastases at the time of operation. It may be that the ultimate prognosis in the two types is totally different.

We wish to thank Mrs Joyce Hoy for her valuable technical assistance.

References

Barka, T., and Anderson, P. J. (1962). Histochemical methods for acid phosphatase using hexazonium pararosanilin as coupler. J. Histochem. Cytochem., 10, 741-753.

Burstone, M. S. (1958a). Histochemical comparison of napthol ASphosphates for the demonstration of phosphatases. J. nat. Cancer. Inst., 20, 601-614.

Burstone, M. S. (1958b). The relationship between fixation and techniques for the histochemical localisation of hydrolytic enzymes. J. Histochem. Cytochem., 6, 322-339.

Burstone, M. S. (1959). New histochemical techniques for the demonstration of tissue oxidase (cytochrome oxidase). $J$. Histochem. Cytochem., 7, 112-122.

Chayen, J., Bitensky, L., Butcher, R. G., and Poulter, L. W. (1969). $A$ Guide to Practical Histochemistry, p. 12. Oliver and Boyd, Edinburgh.

Czernobilsky, B., and Tsou, K. C. (1968). Adenocarcinoma, adenomas and polyps of the colon. Cancer (Philad.), 21, 165-177.

Drury, R. A. B., and Wallington, E. A. (1967). Carlton's Histologica Technique, p. 239. Oxford University Press, London.

Dukes, C. E. (1960). The pathology of rectal cancer. In Neoplastic Disease at Various Sites, edited by D. W. Smithers (Monographs on Neoplastic Disease), Vol. III, pp. 59-68. Livingstone, Edinburgh and London.

Glenner, G. G., Burtner, H. J., and Brown, G. W., Jr. (1957). The histochemical demonstration of monoamine oxidase activity by tetrazolium salt. J. Histochem. Cytochem., 5, 591-599.

Hayashi, M., Nakajima, Y., and Fishman, W. H. (1964). The cytologic demonstration of $\beta$-glucuronidase employing napthol AS-B1 glucuronide and hexazonium pararosanilin: a preliminary report. J. Histochem. Cytochem., 12, 293-297.

Hess, R., Scarpelli, D. G., and Pearse, A. G. E. (1958). The cytochemical localization of oxidative enzymes. II. Pyridine nucleotide-linked dehydrogenases. J. biophys. biochem. Cytol., 4, 753-760.

Nachlas, M. M., and Hannibal, M. J. (1961). Histochemical observations of the polyp-carcinoma sequence. Surg. Gynec. Obstet., 112, 534-542.

Nachlas, M. M., Tsou, K. C., De Souza, E., Cheng, C. S., and Seligman, A. M. (1957). Cytochemical demonstration of succinic dehydrogenase by the use of a new p-nitrophenyl substituted ditetrazole. J. Histochem. Cytochem., 5, 420-436.

Scarpelli, D. G., Hess, R., and Pearse, A. G. E. (1958). The cytochemical localisation of oxidative enzymes. 1. Diphosphopyridine nucleotide diaphorase and triphosphopyridine nucleotide diaphorase. J biophys, biochem. Cytol., 4, 747-752.

Wattenberg, L. W. (1959a). A histochemical study of five oxidative enzymes in carcinoma of the large intestine in man. Amer. $J$. Path., 35, 113-138.

Wattenberg, L. W. (1959b). A histochemical study of succinic dehydrogenase and cytochrome oxidase in proliferative lesions of the large intestine. Cancer Res., 19, 1118-1123. 